\title{
Lymphocytic Choriomeningitis Virus Infections and Seroprevalence, Southern Iraq
}

\author{
Hussein Alburkat, Anne J. Jääskeläinen, Ali M. Barakat, Hassan J. Hasony, \\ Tarja Sironen, Haider Al-hello, Teemu Smura, Olli Vapalahti
}

Acute febrile neurological infection cases in southern Iraq $(\mathrm{N}=212)$ were screened for lymphocytic choriomeningitis virus (LCMV). Two LCMV IgM-positive serum samples and 2 cerebrospinal fluid samples with phylogenetically distinct LCMV strains were found. The overall LCMV seroprevalence was $8.8 \%$. LCMV infections are common and associated with acute neurological disease in Iraq.

T ymphocytic choriomeningitis virus (LCMV) is a rodentborne pathogen that belongs to the genus Mammarenavirus, family Arenaviridae. The house mouse (Mus musculus) is considered the reservoir of LCMV (1). Humans can be infected with LCMV by inhaling particles contaminated with rodent excreta, during organ transplantation, or congenitally during pregnancy (2). The symptoms of LCMV infection range from subclinical to severe (3); severe infections may manifest as meningitis or encephalitis or as a congenital syndrome including microcephaly, for example (4).

Because of the cosmopolitan distribution of its reservoir host, LCMV most likely circulates globally. However, most epidemiologic studies on LCMV have been conducted in Europe, the United States, Japan, and China (5-10). The presence and seroprevalence of LCMV infections in the Middle East region have remained unknown $(11,12)$. We report on LCMV seroprevalence, acute LCMV infections, and characterization of phylogenetically distinct local LCMV strains in southern Iraq.

\section{The Study}

We collected 261 serum samples (from 171 acute febrile patients and 90 healthy controls) in Nasiriyah

Author affiliations: University of Helsinki, Helsinki, Finland

(H. Alburkat, A.J. Jääskeläinen, T. Sironen, T. Smura,

O. Vapalahti); Helsinki University Hospital, Helsinki

(A.J. Jääskeläinen, O. Vapalahti); University of Basrah, Basrah, Iraq (A.M. Barakat, H.J. Hasony); Finnish Institute for Health and Welfare, Helsinki (H. Al-hello)

DOI: https://doi.org/10.3201/eid2612.201792 region, Dhi Qar governorate, southern Iraq (Figure 1) during 2012-2016. In addition, we collected 41 cerebrospinal fluid (CSF) samples from another set of acute febrile patients. All samples were stored at $-70^{\circ} \mathrm{C}$.

We studied the occurrence of LCMV infection in the Nasiriyah region of southern Iraq by screening 171 serum and 41 CSF samples, from patients with fever and neurologic manifestations, for LCMV RNA and IgM and IgG. The inclusion criteria for the study were acute febrile illness and neurologic symptoms such as headache, muscle weakness, or fatigue (Table 1). The mean duration of illness was 4.29 days (range 3-7 days). We used the IgG positivity in serum samples from the symptomatic patients as well as healthy controls to estimate the LCMV seroprevalence in the region. Ethics permissions were obtained and stored in the Al Hussain General Teaching Hospital and Bint Al Huda Maternity and Children Teaching Hospital in the Nasiriyah region, southern Iraq.

We extracted viral RNA from acute infection samples (serum and CSF) $(140 \mu \mathrm{L} /$ sample) using a QIAamp Viral RNA Mini kit (QIAGEN, https://www.qiagen. com) according to the manufacturer's instructions. We performed a pan-arena reverse transcription PCR (RTPCR) using SuperScript II One-Step RT-PCR system with Platinum Taq High Fidelity (Invitrogen, https:/ / www.thermofisher.com), and primers described previously (13). RT-PCR products $(\approx 300-400 \mathrm{bp})$ were sequenced using the Sanger method; sequencing was performed by the Sequencing laboratory of Institute for Molecular Medicine Finland FIMM Technology Centre, University of Helsinki. For antibody detection, indirect LCMV IgM and IgG immunofluorescence assays (IFAs) were conducted, as described previously (6). In general, IFAs are not very specific assays; therefore, one could assume cross-reaction between LCMV and other mammarenaviruses. The specificity and sensitivity of IFA were not examined in this study. 


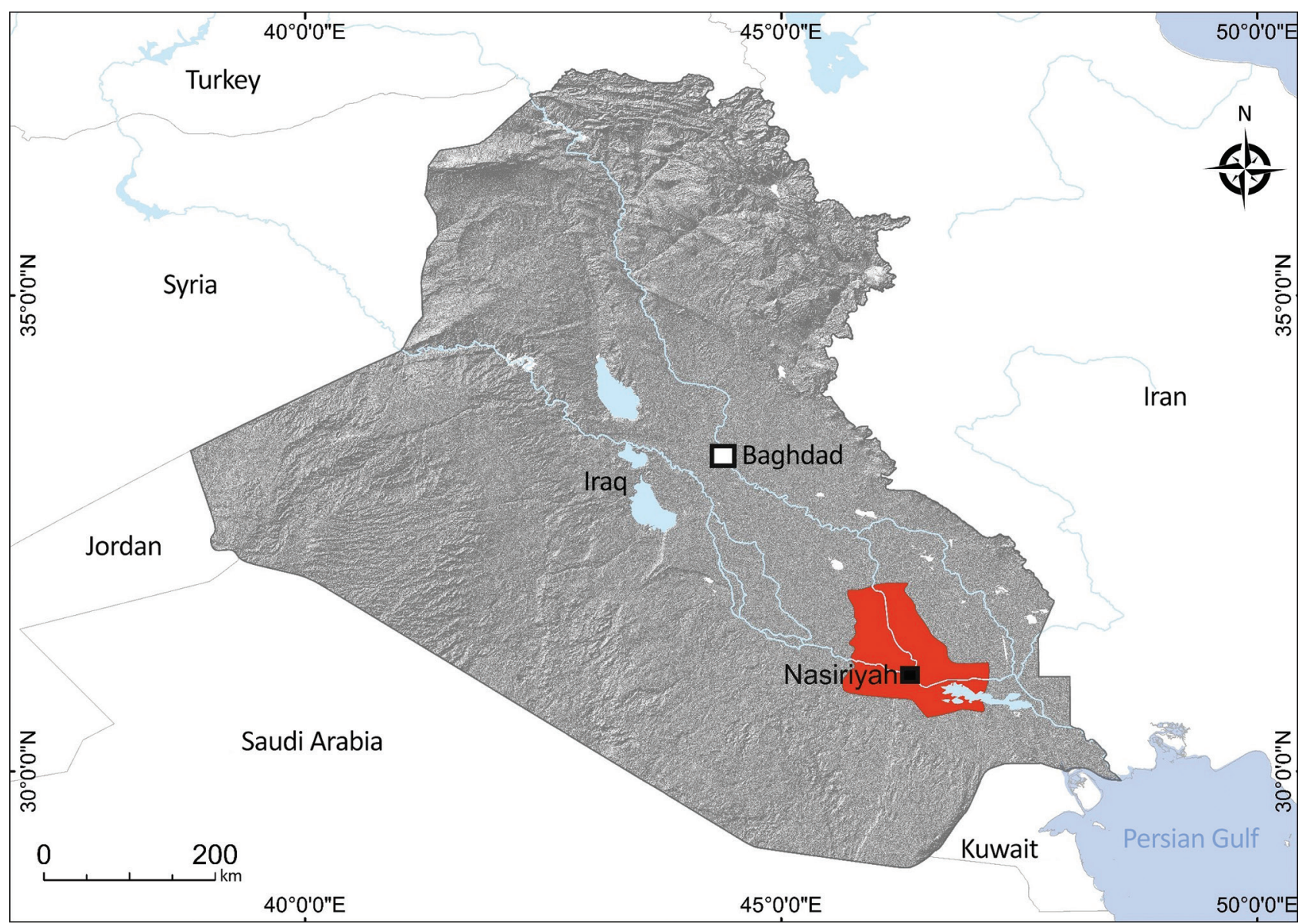

Figure 1. Study site (red) in Dhi Qar Governorate, Nasiriyah region, Iraq, from where serum and cerebrospinal fluid samples were collected from persons in rural and urban areas and screened for lymphocytic choriomeningitis virus.

The serum samples derived from patients with fever and neurologic symptoms were screened by IFA for both LCMV IgM and IgG. LCMV IgM was found in 2 serum samples (2/171) derived from patients with acute febrile illness; both serum samples were negative for LCMV IgG and LCMV RNA. These patients (a 65-year-old woman and a 70-year-old man) had fever and neurologic symptoms (Table 2).

Two CSF samples (from a 35-year-old woman and a 50-year-old man) derived from patients with fever and neurologic symptoms (Table 2) were positive for LCMV RNA by using panarenavirus RT-PCR and sequencing. Phylogenetic analysis showed that both of the sequences (GenBank accession nos. MT093202 for CSF_sample_11_Iraq_2012 and MT093203 for CSF_ sample_64_Iraq_2012) grouped with other LCMV strains but formed a distinct subcluster (Figure 2). No corresponding serum samples were available for these patients, but CSF samples were further tested for LCMV IgM and IgG; all were negative.
Table 1. Signs and symptoms observed among 212 patients with acute febrile illness and neurologic symptoms screened for lymphocytic choriomeningitis virus, southern Iraq

\begin{tabular}{lc}
\hline Sign or symptom & Percentage \\
\hline Fever & 100 \\
Headache & 90 \\
Joint pain & 68 \\
Vertigo & 61 \\
Severe malaise & 48 \\
Chills & 46 \\
Cough & 46 \\
Abdominal pain & 34 \\
Drowsiness & 30 \\
Anorexia & 28 \\
Stiff neck & 28 \\
Nausea & 21 \\
Retroorbital pain & 19 \\
Diarrhea & 18 \\
Vomiting & 10 \\
Confusion & 8 \\
Severe muscle weakness & 6 \\
Conjunctivitis & 3 \\
Lymphadenopathy & 3 \\
Rash & 2 \\
Ataxia & 1 \\
Shortness of breath & 1 \\
\hline
\end{tabular}


Table 2. Clinical observations in 4 patients with test results positive for lymphocytic choriomeningitis virus, southern Iraq*

\begin{tabular}{|c|c|c|c|c|}
\hline \multirow[b]{2}{*}{ Observation } & \multicolumn{2}{|c|}{ CSF RNA-positive patients } & \multicolumn{2}{|c|}{ IgM-positive patients } \\
\hline & Male. no. 11 & Female. no. 64 & Male. no. 61 & Female. no. 38 \\
\hline Diagnosis & Meningoencephalitis & Meningitis & None & No diagnosis \\
\hline Duration of illness & 7 & 4 & 3 & 3 \\
\hline Symptoms & Fever & Fever & Fever & Fever \\
\hline & Chills & Chills & Headache & Chills \\
\hline & Headache & Headache & Drowsiness & Headache \\
\hline & Cough & Cough & Vertigo & General malaise \\
\hline & Retroorbital pain & Retroorbital pain & Joint pain & Vertigo \\
\hline & Severe muscle weakness & Severe malaise & & Abdominal pain \\
\hline & Drowsiness & Drowsiness & & Fatigue \\
\hline & Vertigo & Vertigo & & \\
\hline & $\begin{array}{l}\text { Joint/ bone pain } \\
\text { Stiff neck }\end{array}$ & Joint pain & & \\
\hline
\end{tabular}

${ }^{*} \mathrm{CSF}$, cerebrospinal fluid; LCMV, lymphocytic choriomeningitis virus.

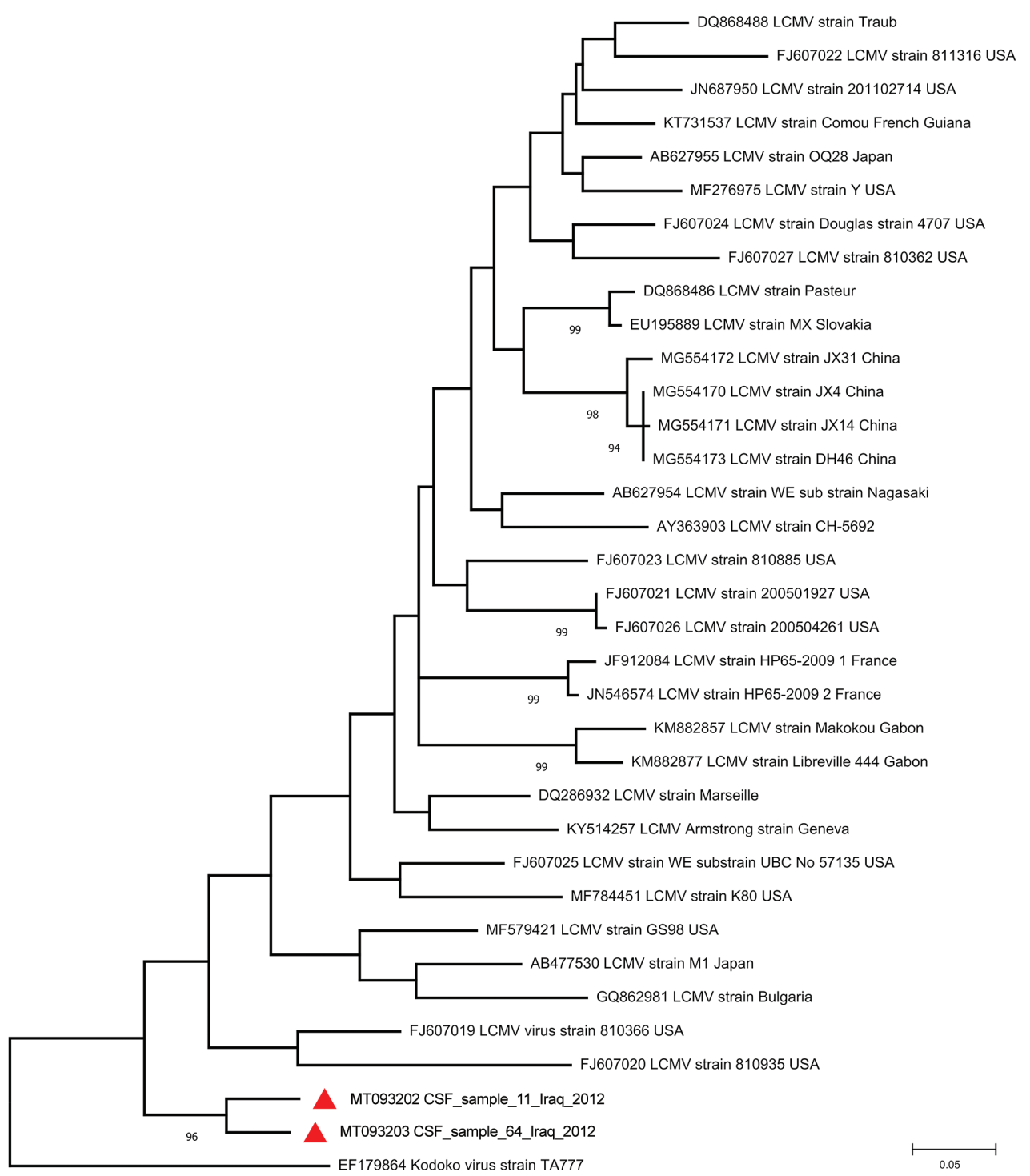

Figure 2. Phylogenetic tree of lymphocytic choriomeningitis virus strains detected in southern Iraq (red triangles) and reference sequences. GenBank accession number, strain name, and country of origin are indicated. Bootstrap support values $>70$ are shown at the nodes. The phylogenetic tree was constructed using MEGA version 7 (https://www.megasoftware.net) and the maximum-likelihood algorithm on the basis of partial large segments of Kodoko virus and partial large segment sequences corresponding to sites 3210-3604 of strain Armstrong (accession no. NC_004291). Scale bar indicates substitutions per nucleic acid site. CSF, cerebrospinal fluid. 
The overall LCMV IgG seroprevalence was 8.8\% $(23 / 261)$ in all serum samples. The seroprevalence of LCMV in our study was $12.2 \%(11 / 90)$ in the healthy control group and $7 \%(12 / 171)$ in the acute febrile patients. This difference was not statistically significant ( $p=0.2$ by $\chi^{2}$ test). Because the patient samples were collected early after onset of illness (3-7 days), IgG had not yet developed; IgG serostatus thus reflects past immunity in this patient group. The healthy control population (mean age 42.9 years) was younger than acute febrile patients (mean age 46.3 years). Healthy men $(7.9 \%)$ were more often LCMV seropositive than were women $(5.6 \%)$, but in patients with acute febrile illness, the gender ratio was reversed (3.9\% in women, $2.8 \%$ in men). The detected LCMV IgG-positive samples were derived from all age groups (21-80 years of age) included in this study. The differences concerning residency, age, and gender were not statistically significant. IgG titers measured among positive samples ranged from 20 to 80 in IFA.

\section{Conclusions}

Only limited information is available on LCMV infections beyond the United States, Europe, Japan, and China. In this work, we focused on both acute febrile infections (presence of IgM antibodies in serum or LCMV RNA in CSF) and seroprevalence of LCMV in southern Iraq. Considerable LCMV seroprevalence was detected in the Nasiriyah region of southern Iraq, and acute LCMV infection was confirmed by demonstration of LCMV RNA in 2 CSF samples and IgM antibodies in 2 serum samples. The phylogenetic analyses of these 2 findings revealed that the new sequences formed a unique subcluster, ancestral to previously known LCMV strains.

Overall, the seroprevalence rate $(8.8 \%)$ of LCMV infection characterized in this study is in line with seroprevalences detected earlier in many countries in Europe, in which it varies from $5.0 \%$ in Finland (14) to $36 \%$ in a special subset in a rural area of the northern Croatian island of Vir (15). Collectively, the seroprevalence and detection of acute infection, including 2 phylogenetically distinct sequences, provide evidence that LCMV circulates in southern Iraq, and it is causing infections leading to acute neurologic manifestations in the population. More sequence data are needed to extend the knowledge on the molecular epidemiology and evolution of LCMV. In addition, further research to characterize LCMV in rodent reservoirs in southern Iraq is needed to plan vector control and public health recommendations.

\section{Acknowledgments}

We gratefully thank Ruut Uusitalo for her assistance in creating the map of Iraq.

This study was partially funded by a research grant to O.V. from the Sigrid Jusélius Foundation and from Helsinki University Hospital Funds.

\section{About the Author}

Mr. Alburkat is a PhD student at the Faculty of Medicine, Haartman Institute, University of Helsinki, Finland. His main research interests include emerging and reemerging rodent-borne viruses, virus evolution, and new pathogen discovery using next-generation sequencing techniques.

\section{References}

1. Zhou X, Ramachandran S, Mann M, Popkin DL. Role of lymphocytic choriomeningitis virus (LCMV) in understanding viral immunology: past, present and future. Viruses. 2012;4:2650-69. https:/ / doi.org/10.3390/v4112650

2. Fischer SA, Graham MB, Kuehnert MJ, Kotton CN, Srinivasan A, Marty FM, et al.; LCMV in Transplant Recipients Investigation Team. Transmission of lymphocytic choriomeningitis virus by organ transplantation. N Engl J Med. 2006;354:2235-49. https://doi.org/10.1056/ NEJMoa053240

3. Bonthius DJ, Mahoney J, Buchmeier MJ, Karacay B, Taggard D. Critical role for glial cells in the propagation and spread of lymphocytic choriomeningitis virus in the developing rat brain. J Virol. 2002;76:6618-35. https://doi.org/10.1128/JVI.76.13.6618-6635.2002

4. Barton LL, Hyndman NJ. Lymphocytic choriomeningitis virus: reemerging central nervous system pathogen. Pediatrics. 2000;105:e35. https://doi.org/10.1542/ peds.105.3.e35

5. Blasdell KR, Duong V, Eloit M, Chretien F, Ly S, Hul V, et al. Evidence of human infection by a new mammarenavirus endemic to Southeastern Asia. eLife. 2016;5:e13135. https://doi.org/10.7554/eLife.13135

6. Kallio-Kokko H, Laakkonen J, Rizzoli A, Tagliapietra V, Cattadori I, Perkins SE, et al. Hantavirus and arenavirus antibody prevalence in rodents and humans in Trentino, Northern Italy. Epidemiol Infect. 2006;134:830-6. https:// doi.org/10.1017/S0950268805005431

7. Knust B, Macneil A, Wong SJ, Backenson PB, Gibbons A, Rollin PE, et al. Exposure to lymphocytic choriomeningitis virus, New York, USA. Emerg Infect Dis. 2011;17:1324-5. https:// doi.org/10.3201/eid1707.101349

8. Knust B, Ströher U, Edison L, Albariño CG, Lovejoy J, Armeanu E, et al. Lymphocytic choriomeningitis virus in employees and mice at multipremises feeder-rodent operation, United States, 2012. Emerg Infect Dis. 2014;20:2407. https:// doi.org/10.3201/eid2002.130860

9. Leibler JH, Zakhour CM, Gadhoke P, Gaeta JM. Zoonotic and vector-borne infections among urban homeless and marginalized people in the United States and Europe, 1990-2014. Vector Borne Zoonotic Dis. 2016;16:435-44. https:/ / doi.org/10.1089/vbz.2015.1863

10. Takagi T, Ohsawa M, Morita C, Sato H, Ohsawa K. Genomic analysis and pathogenic characteristics of lymphocytic choriomeningitis virus strains isolated in Japan. Comp Med. 2012;62:185-92. 
11. Albariño CG, Palacios G, Khristova ML, Erickson BR, Carroll SA, Comer JA, et al. High diversity and ancient common ancestry of lymphocytic choriomeningitis virus. Emerg Infect Dis. 2010;16:1093-100. https:/ / doi.org/ 10.3201/eid1607.091902

12. Zhang L, Li S, Huang SJ, Wang ZD, Wei F, Feng XM, et al. Isolation and genomic characterization of lymphocytic choriomeningitis virus in ticks from northeastern China. Transbound Emerg Dis. 2018;65:1733-9. https://doi.org/ 10.1111/tbed.12946

13. Vieth S, Drosten C, Lenz O, Vincent M, Omilabu S, Hass M, et al. RT-PCR assay for detection of Lassa virus and related Old World arenaviruses targeting the L gene. Trans R Soc Trop Med Hyg. 2007;101:1253-64. https:/ / doi.org/10.1016/ j.trstmh.2005.03.018
14. Fevola C, Kuivanen S, Smura T, Vaheri A, Kallio-Kokko H, Hauffe HC, et al. Seroprevalence of lymphocytic choriomeningitis virus and Ljungan virus in Finnish patients with suspected neurological infections. J Med Virol. 2018;90:429-35. https:/ / doi.org/10.1002/ jmv.24966

15. Dobec M, Dzelalija B, Punda-Polic V, Zoric I. High prevalence of antibodies to lymphocytic choriomeningitis virus in a murine typhus endemic region in Croatia. J Med Virol. 2006;78:1643-7. https://doi.org/10.1002/ jmv.20749

Address for correspondence: Hussein Alburkat, Rastilantie 2A 29, Helsinki 00960, Finland; email: hussein.alburkat@helsinki.fi

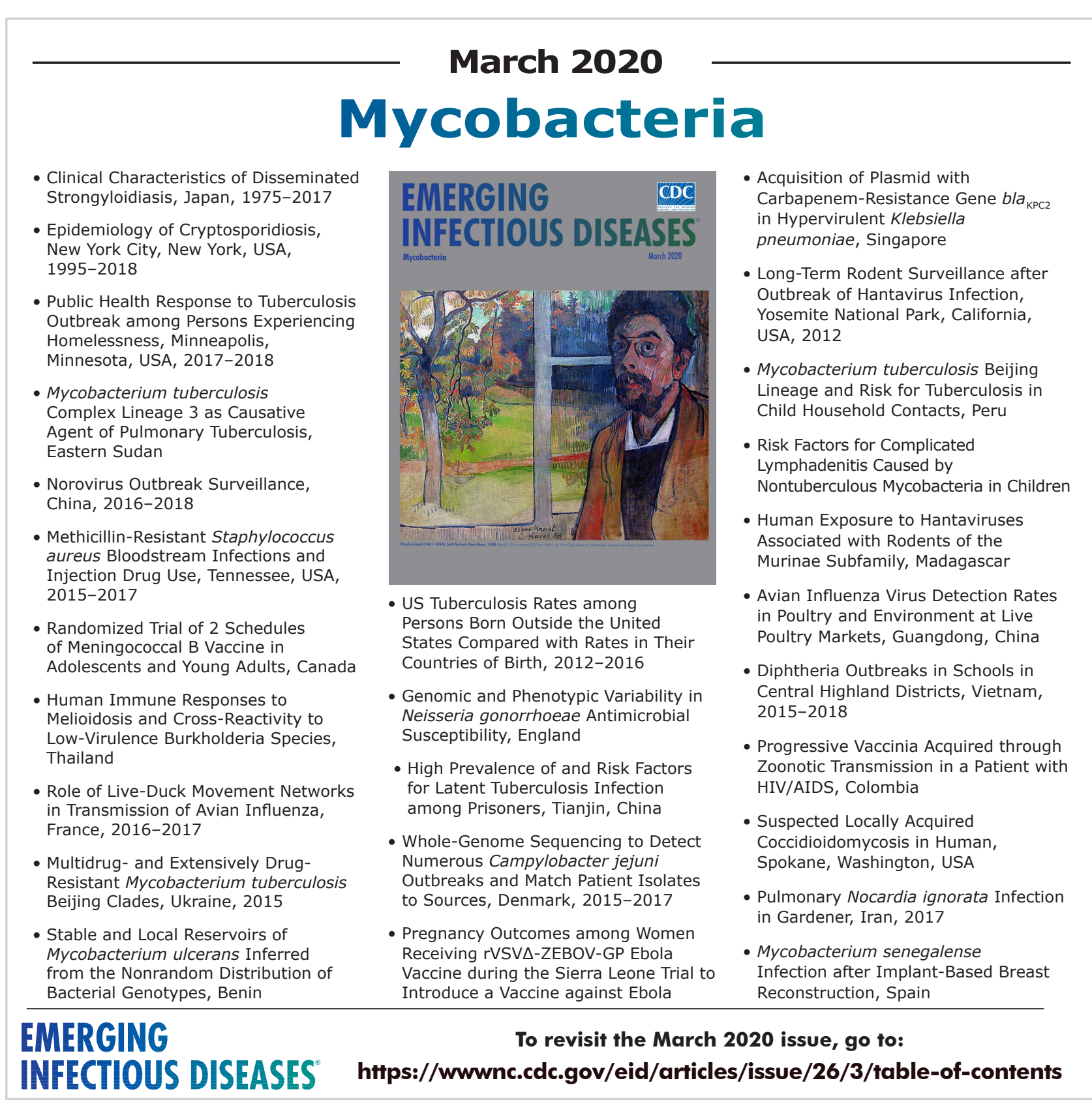

